\title{
Hydraulic driven piston pumps for the transport of pastes and slurries in the mining industry
}

\author{
P Peschken Putzmeister Solid Pumps GmbH, Germany \\ K Kivanc Eti Bakir A.S, Turkey
}

\begin{abstract}
More and more mines are using double piston pumps for conveying pastes, cakes and slurries.

Stiff pastes are normally used for the stabilisation of underground workings. Cement and ash are added to create a construction material with sufficient strength.

For tailings and ore transportation above ground, slurries are produced and transported over long distances to deposits or preparation plants.

With this presentation, we will show various job sites around the world where different materials are pumped, providing the relevant information about the pastes and slurries that were pumped, information about the paste preparation plants, advantages of the paste systems and when to use which type of piston pump.
\end{abstract}

\section{Introduction}

The economy and the environment are subject to continued pressure. This pressure will increase further if resources - in particular, water and energy - continue to become scarcer and the demand continues to rise. This is to be expected.

Naturally, it would be ideal if industrially necessary transport tasks only consumed a small amount of water extracted from the environment as well as the smallest possible amount of energy.

However, this kind of technology or solution will only be used if it is able to compete economically with other alternative transport methods such as pumps, conveyor belt systems, rail and trucks, etc or if there is no alternative method. Today, the idea of there being no alternative is extremely improbable or even unthinkable. There are always alternatives, even if sometimes they are alternatives in name only.

Why pump transport?

- Horizontal and/or vertical transport.

- Material mostly taken up only once.

- Independent of weather.

- Closed system.

- Possibility of transport over great distances.

- Conveyance of large quantities.

- Safe transport system for personnel.

- Low environmental influence.

- Low cost/economical. 
Hydraulic piston pumps and feed systems such as screw conveyors have been used in the industry for around thirty years. Over the course of time, silos and silo discharge technology as well as dosing and mixing technology have been added to these. Engineering and pipelines are often included in the package.

\section{Basic principles}

\subsection{Transport of high-density substances}

High-density substances are a mixture of liquid and solid components. The mixtures differ in their characteristic physical and chemical properties, such as their specific weight, dry matter content, and maximum particle size. Stiffer mixtures with higher dry matter content are called paste. In individual cases, tests must be carried out to determine the dry substance content up to which a material can still be pumped, and to find out which delivery pressures and operating parameters are required.

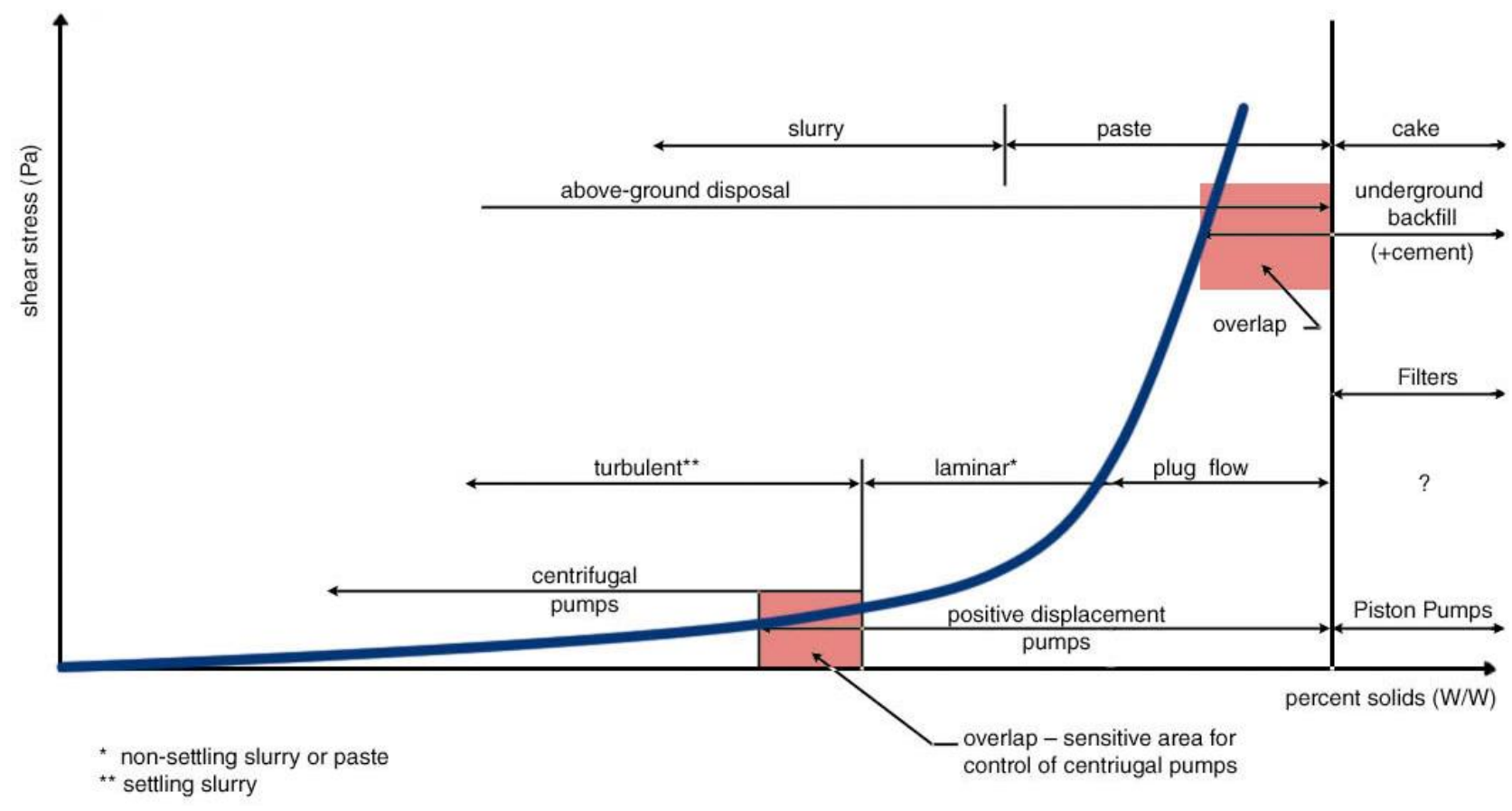

\section{Figure 1 High-density substance classification - transition from slurry to paste (adapted from Jewell 2006)}

The operators of industrial plants are increasingly being faced with the challenge of how to convey substances with a high content of solids over large distances to subsequent handling processes. Alternative conveyance options are available here, such as conveyors, screw conveyors or transport by truck or rail. There are limits to mechanical delivery systems both in plant planning and in plant design. It is easier to pump high-density substances in a closed pipeline using high-density solids pumps. This technology is low-noise and odour-free. The pipelines can be integrated into the existing plant, to save space and for flexibility. Today, delivery lines of many kilometres can be implemented, e.g. for the transport of ash, slag and tailings to disposal sites. 


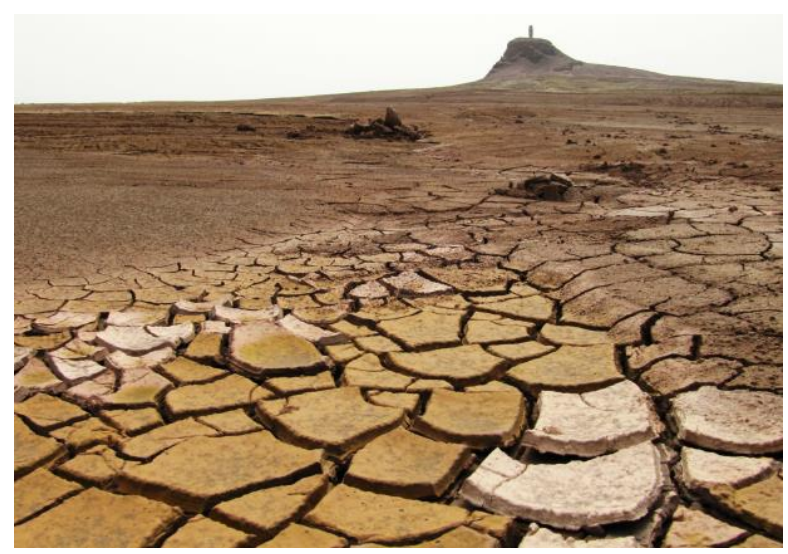

\section{Figure 2 Paste-like waste from bauxite processing}

Hydraulic piston pumps can be used for this in a wide range of applications and can even pump highly viscous, solids-containing media and extremely dry media. A dry substance content of up to $85 \% \mathrm{w} / \mathrm{w}$ is possible.

From a technical procedural point of view, this gives rise to a range of advantages.

\subsection{Water requirement and energy consumption}

The high solids content of the pumped material in the form of a paste, for example, means that the water content is correspondingly small. This saves on resources due to the low consumption of water and results in a lower environmental burden. Moreover, the required energy is used mainly to convey the solids, and not to transport water.

For the conveyance of high-density substances to disposal sites, transport that uses a small amount of water has a range of advantages, especially for the disposal of fly ash, bottom ash and excavated material:

- Reduced water requirement in comparison with slurry backfill.

- Longer life of the disposal site, same land requirement.

- Hardly any seepage water, which protects the groundwater.

- Hardly any free water at the disposal site.

- No risk of dam failure.

- Stabilisation of excavated material by means of evaporation.

- Advanced reclamation.

- For all of these reasons, better acceptance of mining among the public.

The conveyance of backfill material with a small water content underground has the advantage that increased strengths can be reached with a lower consumption of cement, if this is required.

\subsection{Delivery pressure and delivery rate - long delivery sections}

Thanks to the ongoing movement over the last few years towards larger delivery rates, delivery pressures of up to 150 bar at a delivery rate of $250 \mathrm{~m}^{3} / \mathrm{h}$ are now available for the hydraulic driven double piston pump series. Moreover, at a delivery pressure of $100 \mathrm{bar}$, a delivery rate of $400 \mathrm{~m}^{3} / \mathrm{h}$ is reached.

Depending on the consistency of the material, this enables conveyance over a pump section of many kilometres horizontally and up to one kilometre vertically. If necessary, several pumps can be connected in a series to extend the achievable pumping distance. For greater delivery rates, pumps can be operated in parallel. 

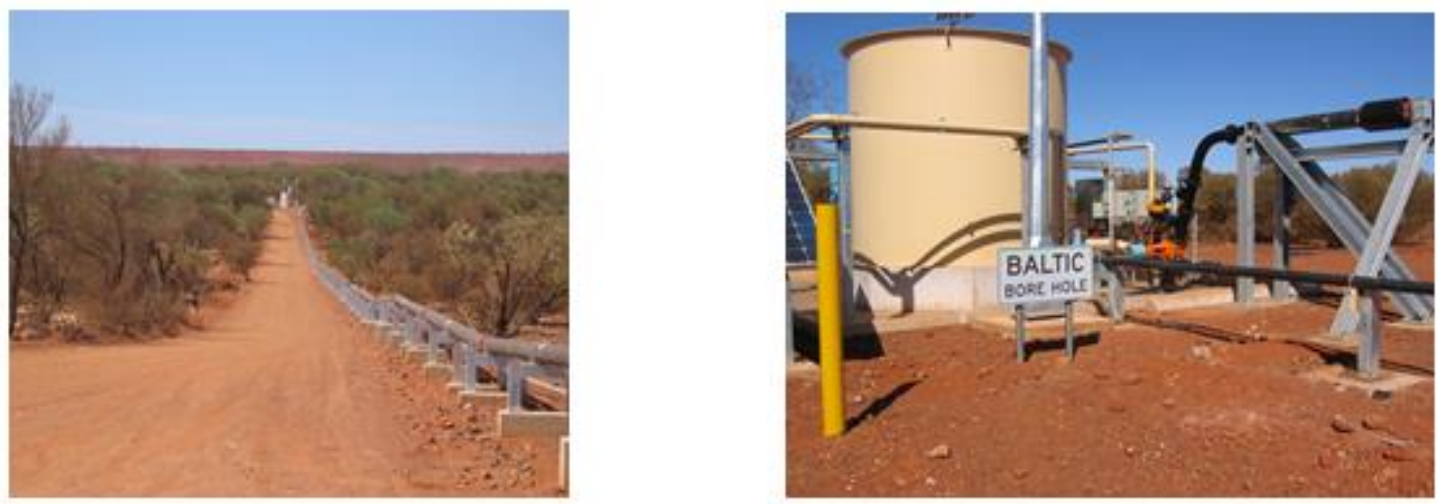

Figure 3 Delivery line to site of placement of backfill material

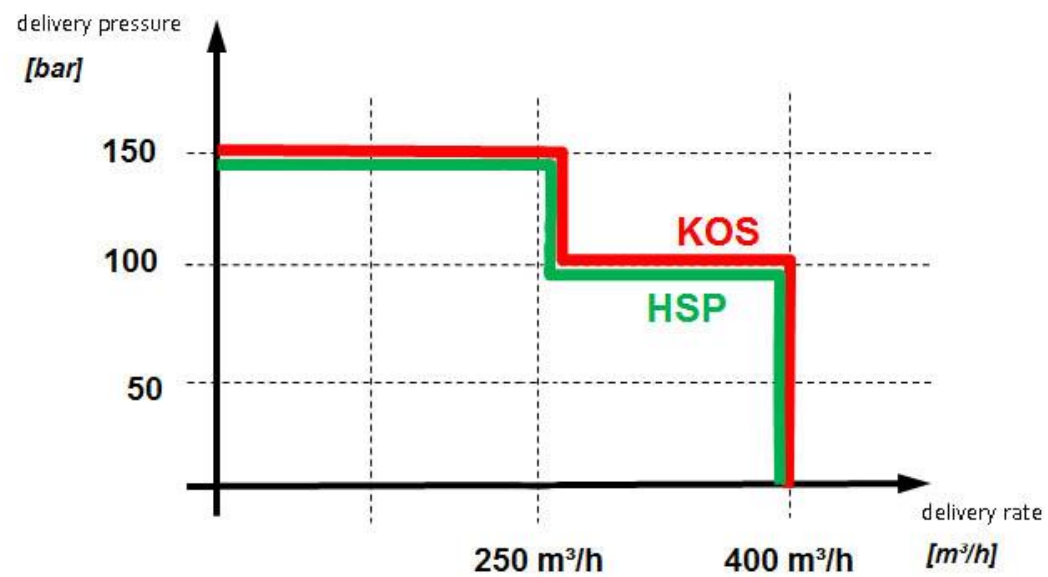

Figure 4 Delivery rates and pressures of KOS and HSP pumps

\section{$3 \quad$ Machine technology}

\subsection{KOS series - pump with S-transfer tube}

In the case of the KOS pump series, the material is placed into a hopper and, from there, sucked into the delivery cylinder during the intake stroke. The delivery stroke pushes the material into the delivery line through an S-transfer tube. At the end of each stroke, the S-transfer tube is switched over within $0.5 \mathrm{~s}$ (change-over phase) by means of powerful plunger cylinders, so that the next stroke cycle can start. The fast change-over time of the S-transfer tube means that there are only short interruptions in the output flow rate, which is advantageous with regard to pulsation.

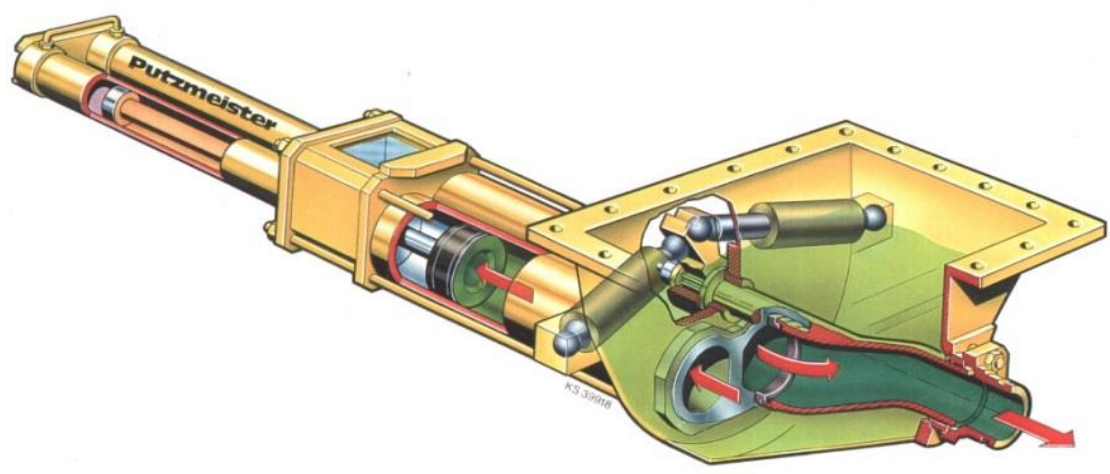

Figure 5 KOS series high-density solids pump with hopper and S-transfer tube (Zey 1999) 


\subsubsection{Particle size - not sensitive to foreign bodies}

The KOS pump with S-transfer tube has the major advantage of being able to pump particle sizes of up to $60 \mathrm{~mm}$ without incident. This enables many possibilities for paste composition and improves cost-effectiveness.

Due to its special design, the pump works without valves or any other narrowed sections. For the conveyed medium, this results in a constantly 'clear passage' over the entire cross section of the pipe. This means that the machine is not sensitive to relatively large foreign bodies (which can be up to $70 \%$ of the diameter of the pump's pressure connection) and obstructions that sometimes occur. Blockages are thus prevented, providing a high level of machine availability and minimising downtime. The advantage of being able to pump larger particle sizes may be relevant, for example, when conveying coarse-grained crude ore for further processing. Naturally, fine ore and finely ground material can also be pumped. Furthermore, in the power plant sector, fly and bottom ashes with a high content of foreign bodies and obstructions can be pumped without difficulty as a mixture.

\subsubsection{Higher outputs - larger machines}

The KOS 25200 HP was developed in 2012/2013 in order to meet the demand for higher delivery rates at high delivery pressures. The technical data is impressive.

- Delivery cylinder diameter: $560 \mathrm{~mm}$.

- Delivery cylinder length: $2,500 \mathrm{~mm}$.

- Delivery rate: $400 \mathrm{~m}^{3} / \mathrm{h}$.

- Delivery pressure: 100 bar.

- Machine weight: $35 \mathrm{t}$.

- Drive output: $1,600 \mathrm{~kW}$.

This makes the machine the most powerful in its class, with the world's largest S-transfer tube.

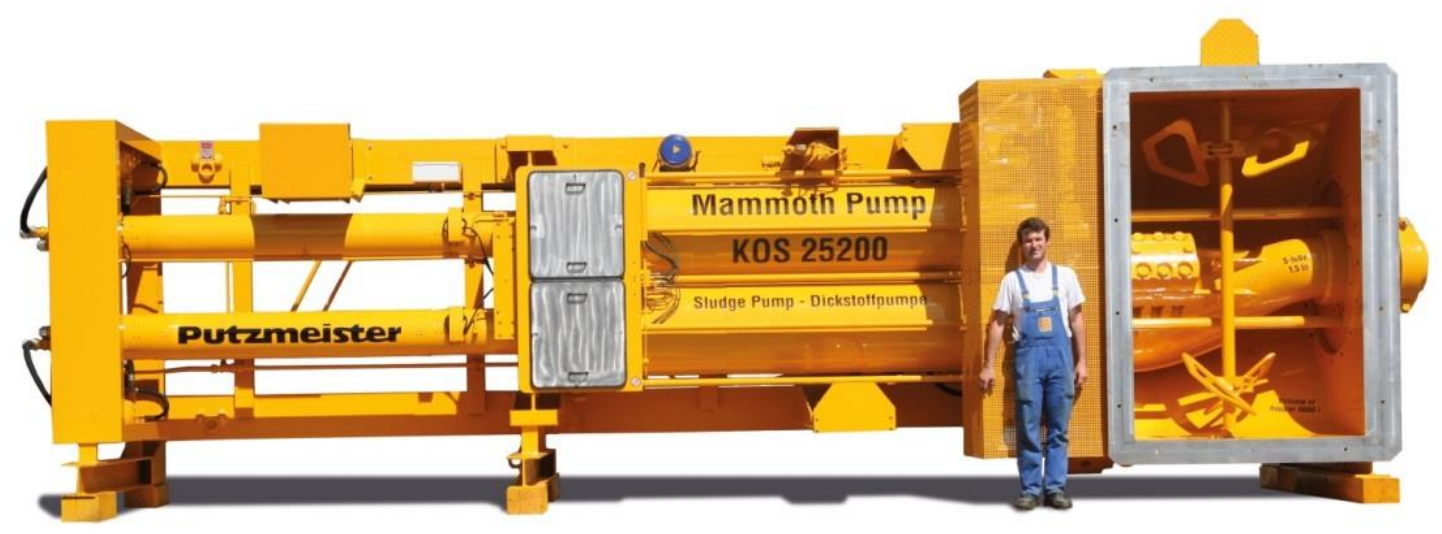

\section{Figure 6 KOS 25200 S-transfer tube machine}

\subsection{HSP series - seat valve pump}

The HSP pump series has a pump head with hydraulically driven seat valves instead of a hopper and S-transfer tube. The appropriate cyclical opening and closing of the valves controls the material flow from its intake up to its introduction into the delivery line. This means that the machine is suitable for fine-grain material with a high solids content, such as finely ground tailings. 


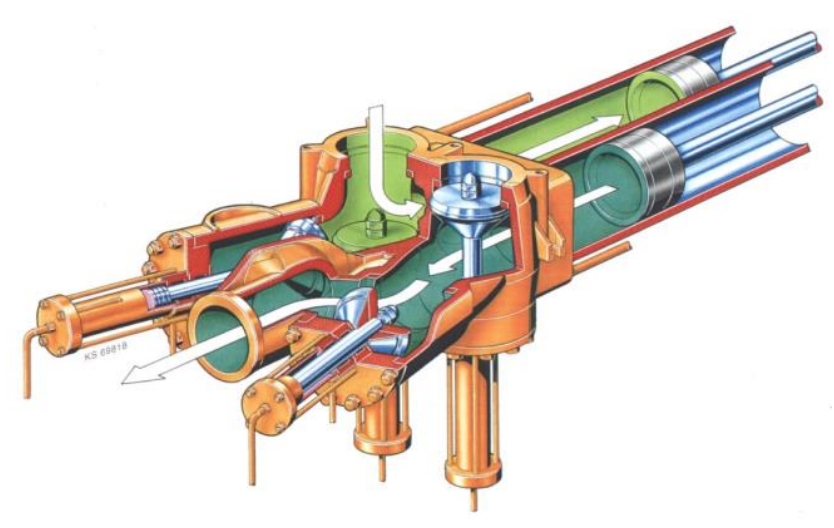

Figure 7 HSP pump head with hydraulically driven seat valves. The wear parts (plate and seat) are available in different material pairings and geometric designs to be selected in accordance with the pumped medium

\subsection{Pulsation damping}

The Putzmeister Constant Flow function (PCF) is unique for a double piston pump. This operating method enables an almost continuous output flow rate in applications that require a low-pulsation pressure curve.

The two delivery cylinders are driven separately from each other via their own hydraulic system, and a constant output flow rate with very low residual pulsation (max. +/- 8\%) is achieved by means of an appropriate control sequence. This reduces the transmission of power and the dynamic load of the delivery line and its mounting, which contributes to a lower risk of plant failure.

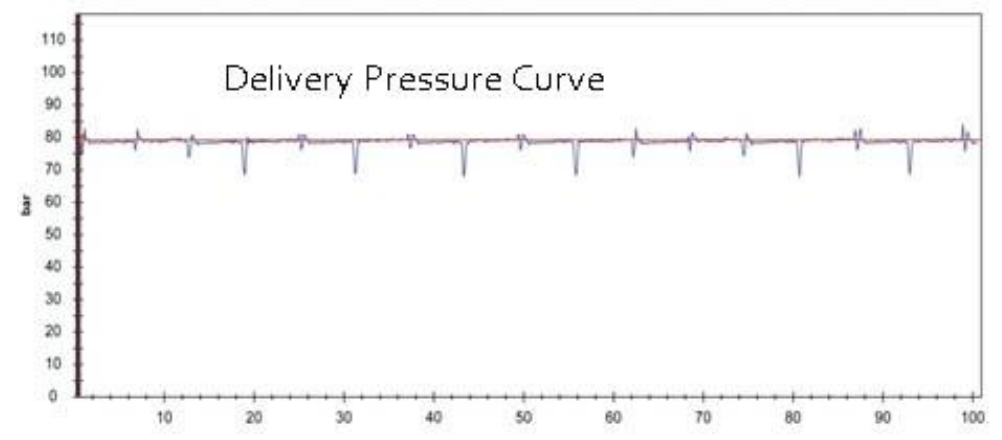

Figure 8 Pulsation-free delivery pressure curve

If the requirements placed upon pulsation damping are in the range of $30 \%$, pulsation dampers that work in accordance with the accumulator (air vessel) principle might be used. These damping systems can be used for all double piston pumps. 


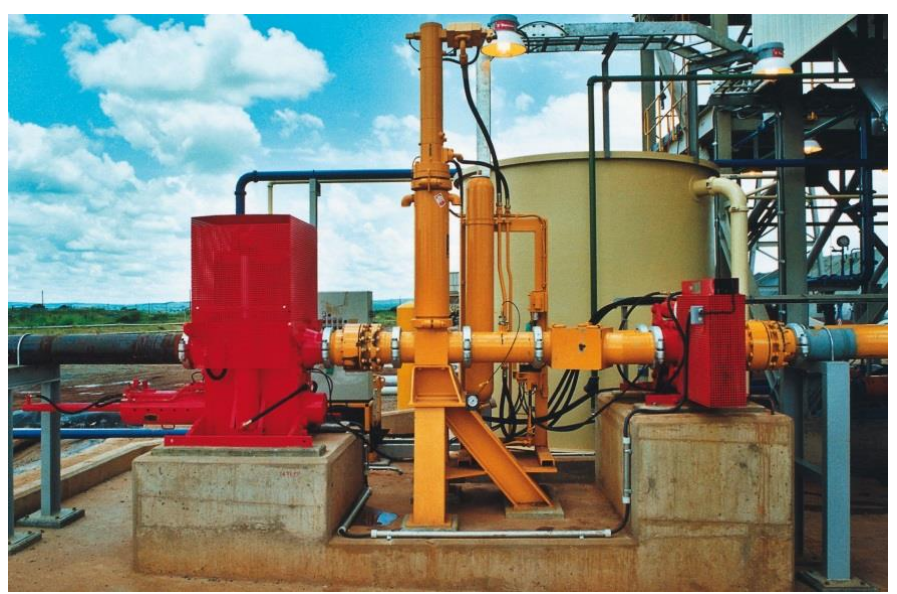

Figure 9 Scraper pig gate; damper; gate valve (left to right)

\subsection{Hydraulic power packs and control cabinet}

Hydraulic packs of different sizes are used to drive the high-density solids pumps. The current power range is $7.5-1,600 \mathrm{~kW}$. The hydraulic pumps are usually driven by electric motors, at low, medium or high voltage with speeds of 1,500 or $1,800 \mathrm{rpm}$, depending on the design. Diesel engines are seldom used for industrial application. The in-line method is applied consistently for the positioning of the pump train, i.e. all hydraulic pumps are driven by one motor. This produces the highest possible level of flexibility for designing the pump train in line with the needs of the plant. It is also important to note that the hydraulic fluid reservoir is generally above the hydraulic pumps. This prevents cavitation and results in optimum intake conditions for the pumps.

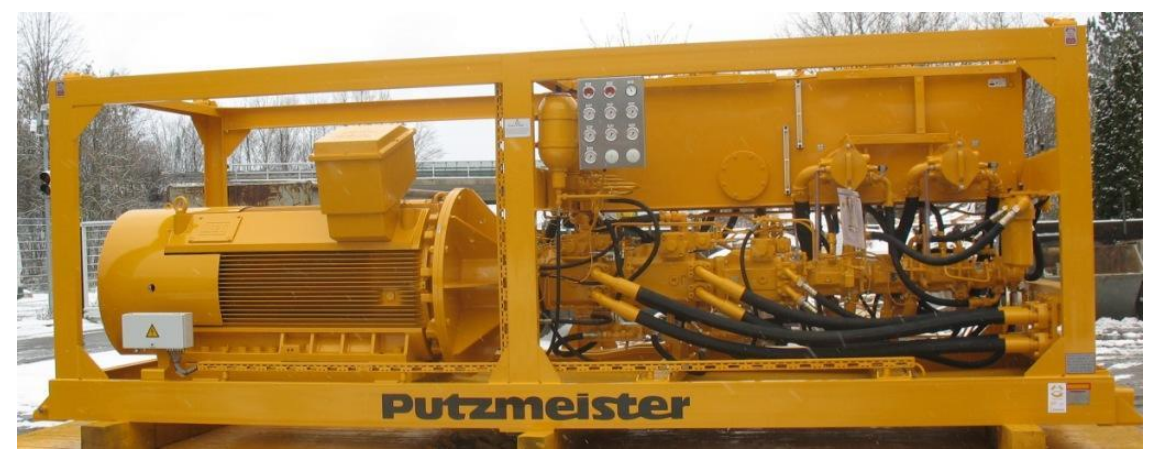

\section{Figure 10 Hydraulic pack, 400 kW power class}

The system is completed by a control cabinet and Programmable Logic Controller (PLC). These form the control and switching centres for operating the high-density solids pump or pumping plant. The control cabinet is fitted with an operating panel that allows the operator to call up all relevant operating data. Standard features include fault logging and the possibility of connecting the control system up to a higher-level control room using various bus systems.

\section{$4 \quad$ Systems engineering}

As well as the actual pumping of high-density substances, a whole range of further steps and plant components play a significant part in the overall process. Here are just a few:

- Storage of high-density substances using silo systems or a jumbo trough.

- Preparation of high-density substances using centrifuges, mixers or shredders.

- Pipeline systems with shut-off and diverter valves.

- Pressure fluctuation dampers for pipelines. 
- Scraper pig gates for pipeline cleaning.

- Instruments with measurement sensors and fill level measurement.

\section{Practical examples for surface disposal and underground usage of excavated material}

Mining produces large quantities of excavated material. For example, 1,000 kg of high-quality ore from the Bulyanhulu Mine in Tanzania contains just $8 \mathrm{~g}$ of gold. The ore is very finely ground to yield as much gold as possible.

Water is added to this excavated material to form a paste. Successful projects have been carried out for the mining of gold, silver, copper, lead, zinc, aluminium, tungsten, nickel, salt and coal.

\subsection{Surface disposal of excavated material as paste}

The Bulyanhulu Mine, owned by Barrick Gold Corp., has been pumping a paste with a $25.4 \mathrm{~cm}$ slump since 2001. Two seat valve double piston pumps of the type HSP 25100 HP are used, both of which are driven by an HA 315 E hydraulic pack with $315 \mathrm{~kW}$ drive power. Each of the pumps can pump $700,000 \mathrm{~m}^{3} / \mathrm{y}$. The pumping distance is approximately $2,500 \mathrm{~m}$.

The silicate-containing material is extremely abrasive and has a Miller number of 197 . The specific weight of the paste is $1,970 \mathrm{~kg} / \mathrm{m}^{3}$, with a solids content of $75 \% \mathrm{w} / \mathrm{w}$. The D50 value is less than $20 \mu \mathrm{m}$, and the maximum particle size is less than $200 \mu \mathrm{m}$.

Design data:

- Delivery rate: $80 \mathrm{~m}^{3} / \mathrm{h}$

- Delivery pressure: 80 bar
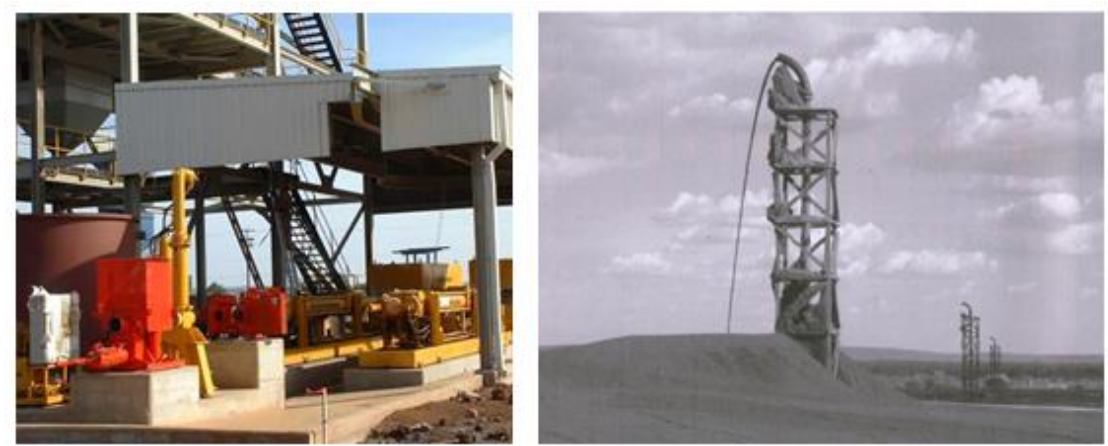

Figure 11 Pumping plant (left); and distribution tower at disposal site (right)

\subsection{Usage of tailings with cement for underground stabilisation}

\subsubsection{Backfilling of fine-grained tailings at the Eti Bakir Copper Mine/Küre, Turkey}

At the Eti Bakir Mine, copper and pyrite concentrate is produced. The chalcopyrite copper ore is crushed and milled by a rod and ball mill and then send to the flotation process. The produced copper concentrate has $17-18 \%$ copper content.

The tailings are quite heavy, with a specific gravity of approximately $3.87 \mathrm{t} / \mathrm{m}^{3}$. A solid concentration of $80-85 \%$ by weight can be achieved. The cement content is $8-9 \%$ and the $\mathrm{pH}$ value is $11-11.5$. The density of the paste is $2.5 \mathrm{t} / \mathrm{m}^{3}$. With a maximum grain size of $106 \mu \mathrm{m}$, the paste is best suitable for a HSP 2180 HPS seat valve pump. The piston pump is driven by a hydraulic power pack with $315 \mathrm{~kW}$ and PCF control. 


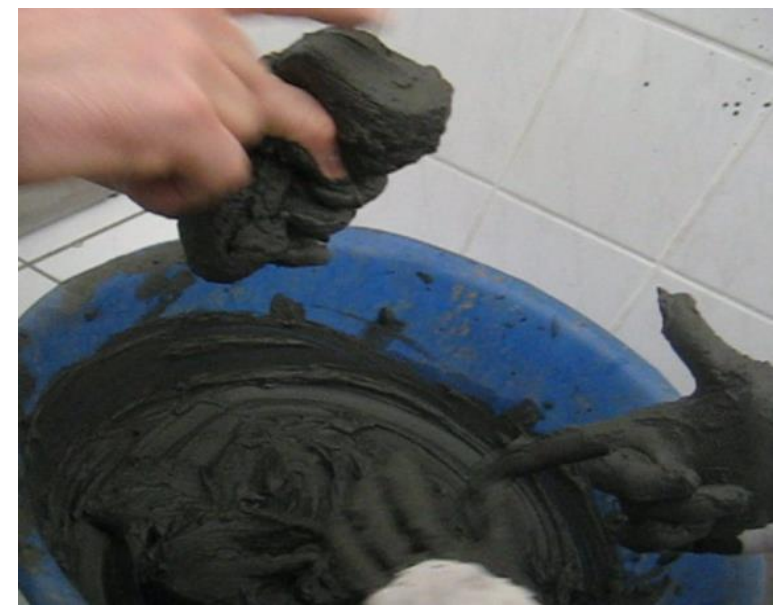

\section{Figure 12 Cemented copper tailings paste}

The pumping distance is $830 \mathrm{~m}$ horizontal above ground, $290 \mathrm{~m}$ vertical down and $380 \mathrm{~m}$ underground. Pumping up to $60 \mathrm{~m}^{3} / \mathrm{h}$ at a maximum delivery pressure of 50 bar, the 1,500 $\mathrm{m}$ can be achieved. For longer distances coming up in future, up to 80 bar at $60 \mathrm{~m}^{3} / \mathrm{h}$ can be achieved, and up to 150 bar at smaller output. The inner pipeline diameter is $142 \mathrm{~mm}$.

\section{Table 1 Particle size distribution for Eti Bakir tailings}

\begin{tabular}{ccc}
\hline Grain size & (\%) & Cumulative \\
\hline$+106 \mu$ & 4.90 & 100 \\
$+75 \mu$ & 7.74 & 95.10 \\
$+53 \mu$ & 14.43 & 87.36 \\
$+38 \mu$ & 31.42 & 72.93 \\
$+20 \mu$ & 27.36 & 41.51 \\
$-20 \mu$ & 14.15 & 14.15 \\
\hline
\end{tabular}

The most important advantages of backfilling at the Eti Bakir Mine are the following:

- Backfilling of tailings underground reduces the costs of the surface tailings deposit area and the risk of embankment failure at the tailings deposit.

- The environmental control of the heavy metal pollution and acid mine drainage (AMD) is another advantage.

- Furthermore, the backfill operation is more favourable compared to rockfill and hydraulic fill in terms of operation costs. 


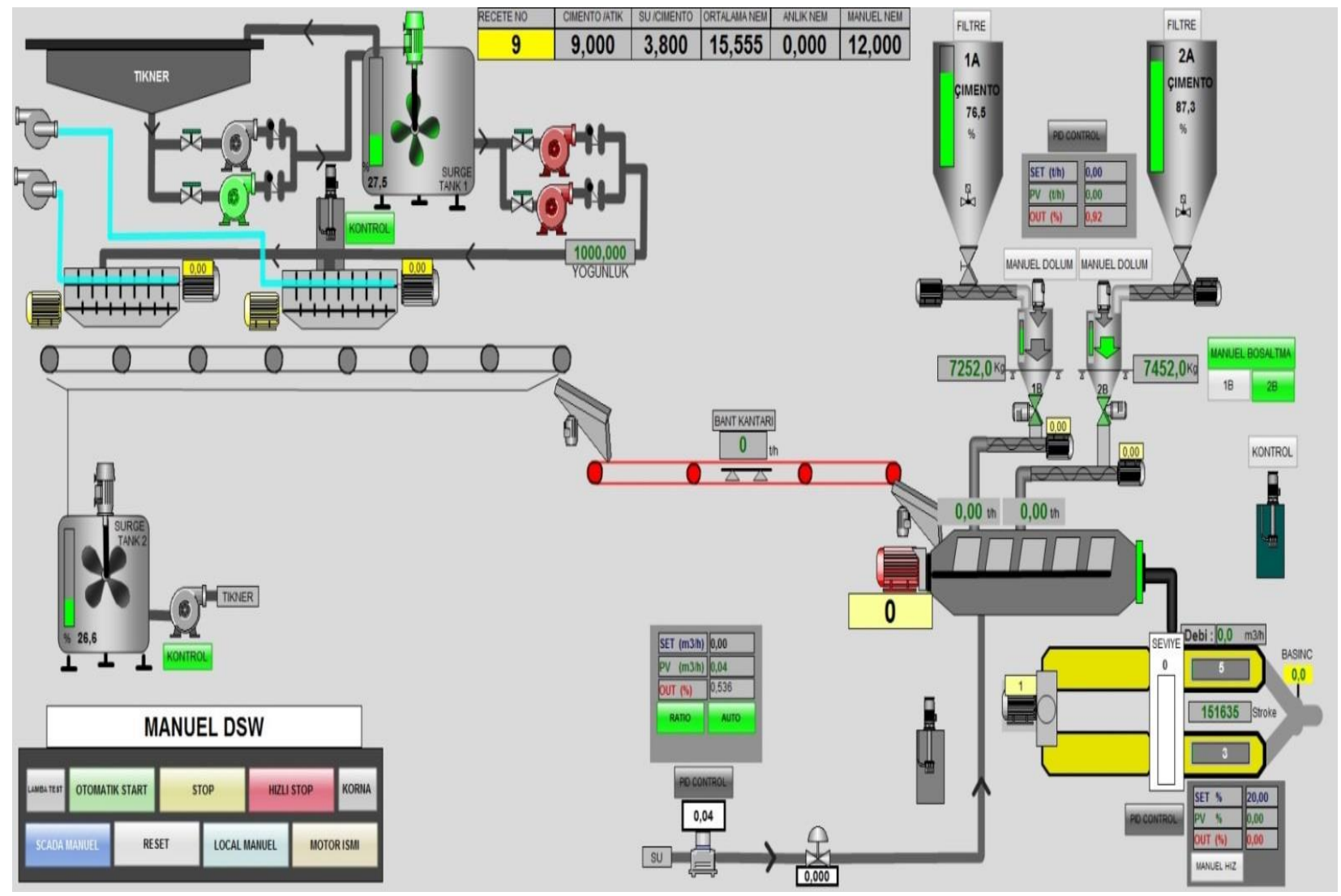

Figure 13 Overview of the tailings preparation plant at Eti Bakir (basic flow sheet)

The tailings are sent to a thickener. The thickener underflow is pumped to a surge tank and from there to disc filters. The tailings with a solid content of $88-91 \%$ by weight are transported by a conveyor belt over a weighing belt into a continuous mixer. There, cement and water are added and the paste with a slump of 7.5-8 in (190.5-203.2 $\mathrm{mm}$ ) is sent to the hopper of the piston pump.

Due to the fine-grained material, a seat valve pump of type HSP 2180 HPS for $60 \mathrm{~m}^{3} / \mathrm{h}$ at 80 bar (peak delivery pressure at smaller output is 150 bar), driven by a HA $315 \mathrm{E}-\mathrm{SP}$ with $315 \mathrm{~kW}$ motor and PCF control to reduce the pressure pulses, was chosen.

\subsubsection{Coarse backfill at a Chinese coal mine}

A concrete-type backfill is being introduced to a Chinese mine. This stiff material with a maximum particle size of $25 \mathrm{~mm}$ is first pumped for $850 \mathrm{~m}$ above ground, then conveyed $410 \mathrm{~m}$ vertically downwards through a steel pipeline feed in a borehole, and then pumped approximately a further $1,000 \mathrm{~m}$ below ground. A delivery pressure of 70 bar is required for this distance.

Two KOS 25100 HP pumps, each driven by an HA $500 \mathrm{E}$, are used for this. One pump is in active use while the other is on standby, to ensure redundancy.

The KOS S-transfer tube pump has the advantage of being able to pump particle sizes of up to $50 \mathrm{~mm}$ without difficulty. This enables many possibilities for paste composition and improves cost-effectiveness. The aim is to prevent mining subsidence.

Design data:

- Delivery rate: $150 \mathrm{~m}^{3} / \mathrm{h}$

- Maximum delivery pressure: 100 bar 


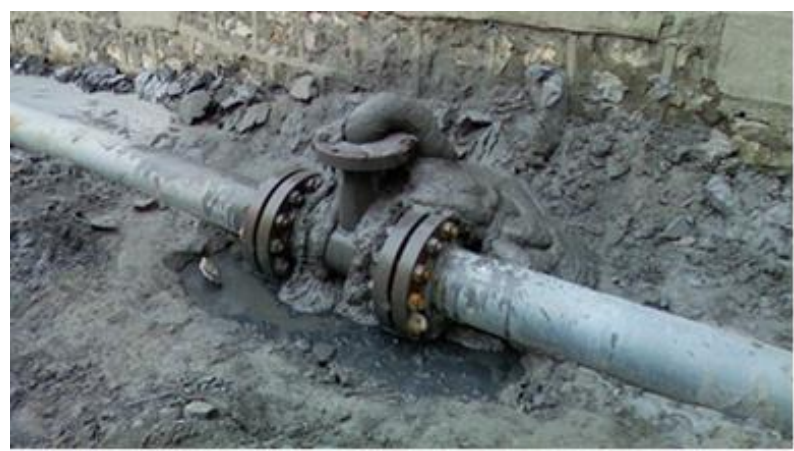

\section{Figure 14 Concrete-type backfill}

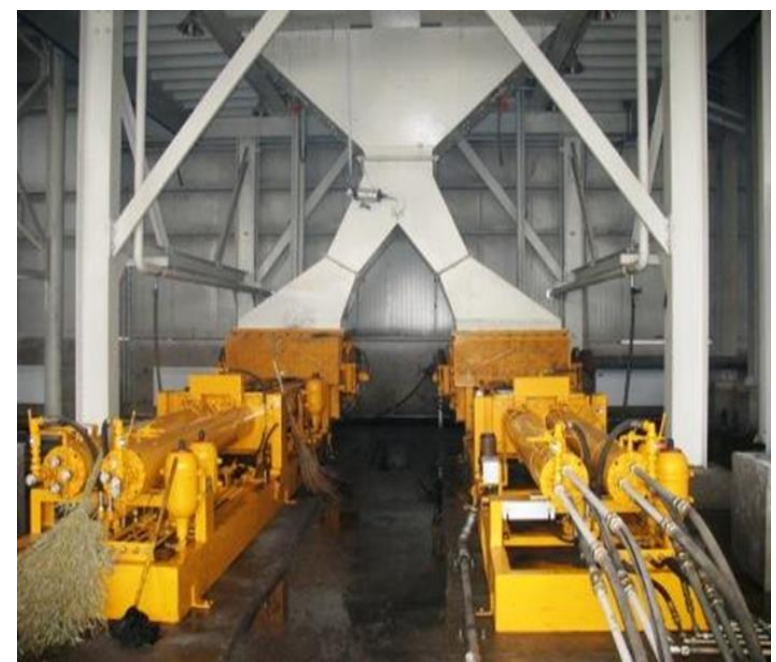

\section{Figure 15 Two KOS 25100 HPs with combined material feed}

Increased cost-effectiveness and safety below ground are factors in favour of the use of high-density solids pump backfilling.

Below are some advantages of high-density solids pump backfilling with cement:

- Environmentally acceptable due to no need for surface disposal sites.

- Less mining subsidence.

- Improved geomechanical control of excavation voids.

- Increased work and operational safety below ground.

- Uninterrupted delivery path in pipelines; personnel do not have to touch the excavated material.

- Very little or no residual water in the mined areas.

- No exhaust gas pollution from backfilling vehicles.

- Improved ventilation due to no weather creep.

- Reduced risk of pit fires.

\subsection{Backfilling in potash and salt mining}

At home and abroad, there is an increasing trend for the voids created by the below-ground mining of potash and salt to be refilled with salt concrete or a suspension of $\mathrm{MgCl}_{2}$ solution, $\mathrm{MgO}$ binder, and filter dust to stabilise the rock. Above or below ground, appropriate silos and mixing plants with downstream pumping facilities are installed to convey pumpable material into the voids that need to be filled. 


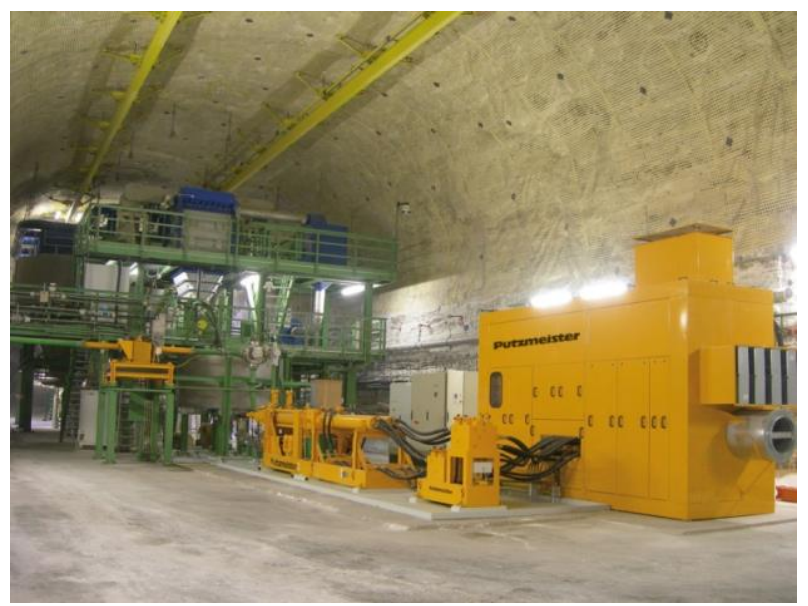

\section{Figure 16 Pumping facility for underground recovery plant in Unterbreizbach}

Since 2004, selected domed voids have been filled with material at the Unterbreizbach below-ground recovery facility (UTV) of $\mathrm{K}+\mathrm{S}$ Kali $\mathrm{GmbH}$. The delivered materials and binders are stored in an above-ground silo. From there, a closed delivery line is used to pneumatically convey them below ground and into the silos of the high-density substance facility. In the mixer of the underground plant, the materials are combined with a salt solution and aggregates on the basis of a specific recipe in order to create a hydraulically pumpable suspension, which is fed into a receiver container. Hydraulically driven seat valve piston pumps are used to pump the suspension through a DN 125 delivery line and into the selected voids, where the material quickly solidifies.

Due to the fine-grained material, three HSP 2180 HP piston pumps were chosen. The pumps are made of stainless steel to avoid corrosion. To reduce pressure drops that arise during pumping due to cylinder change-over, the plants are fitted with the PCF system (see Section 3.3).

\subsection{Pumping fly and bottom ash at the Kogan Creek Power Station, Queensland, Australia}

With $750 \mathrm{MW}$, the Kogan Creek Power Station is the largest single-unit power station in Australia. 2.8 Mt of hard coal will be burnt each year. The local mine is approximately $4,000 \mathrm{~m}$ away from the power plant and with reserves of $300 \mathrm{M} t$ there is enough coal for the next 100 years.

The pumping system was commissioned in 2007. The fly and bottom ash with a maximum grain size of $50 \mathrm{~mm}$ are pumped over a distance of 5,500 $\mathrm{m}$ into a prepared and lined ash cell.

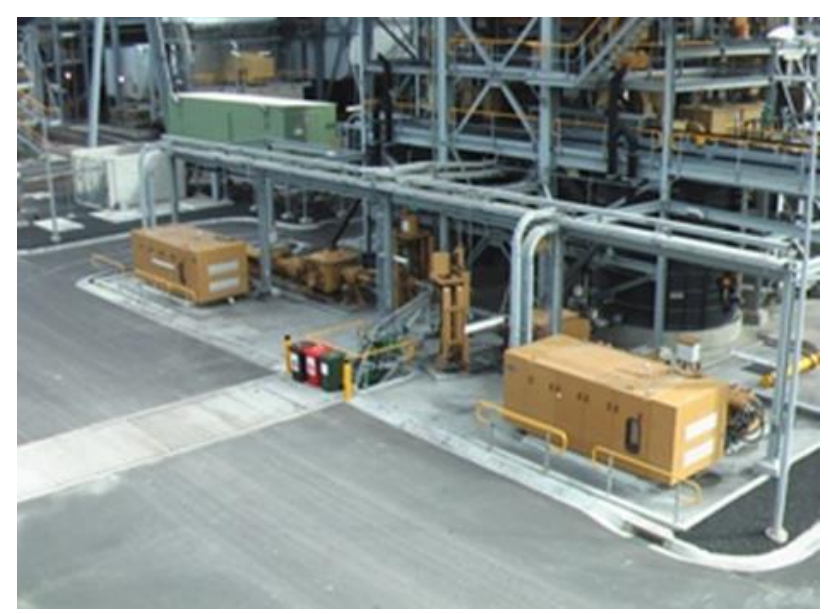

Figure 17 Redundant ash preparation and pumping plant at Kogan Creek 
The ash slurry is mixed by a continuous mixer, and then fed into an intermediate hopper before flowing into the hopper of the piston pump by gravity.

One KOS 25.100 double piston pump with concrete valve, driven by a $500 \mathrm{~kW}$ power pack, pumps up to $110 \mathrm{~m}^{3} / \mathrm{h}$ ash slurry through a $150 \mathrm{~mm}$ diameter pipeline into the pit. The necessary speed in the pipeline was calculated to be $2.35 \mathrm{~m} / \mathrm{s}$ to avoid sedimentation and blockages. Normal operation provides for approximately $50 \mathrm{~m}^{3} / \mathrm{h}$. Sedimentation does not occur at this lower delivery rate due to the very close control of the density. Solids content up to $65 \%$ are present with strict control methodology in place to monitor the ratio between fly ash and bottom ash. The density of the slurry is $1.42 \mathrm{t} / \mathrm{m}^{3}$ and the $\mathrm{pH}$ value is between 9-11. The slurry is very abrasive but not corrosive.

To reduce pressure peaks in the long pipeline, the machine is equipped with a pressure peak damping system. One pumping system is working while the other system is on stand-by.

The big advantage at the deposit is that the material levels itself and it is not necessary to drive in the ash with graders or trucks. The high-density slurry dries very quickly, and it is possible to walk over it after three days.

\section{Summary}

Hydraulic piston pumps for the transport of solids are an alternative to mechanical delivery systems. They can pump high-density substances with a high content of solids and large particles or foreign bodies. The advantages are lower water and energy requirements for the delivery job. In recent years, the limits of machine performance have been pushed higher and higher, larger machines have been developed, and new fields of application have been opened up.

All types of metal mines and coal mines use piston pumps for conveying paste and slurries to deposits above ground, underground for backfill and for transport in preparation plants as well as dewatering of mines.

\section{$7 \quad$ Outlook}

Pushing the limits of pumping, with regard to machine size and machine performance (for example, a vertical delivery height of $1 \mathrm{~km}$ with a single machine), new possibilities that were previously unheard of in this form are now available. Even the conveyance of raw coal to enhance insufficient shaft capacities is possible.

There is no other technology that can rival this method with regard to meeting this combination of requirements of maximum particle size, output and solids content.

\section{Acknowledgement}

The permission to publish results and photographs from Eti Bakir Mine, Plutonic Gold Mine, K+S Kali GmbH and Kogan Creek is greatly appreciated.

\section{References}

Jewell, RJ 2006, 'Figure 1.5 Indicative ranges of properties for different purposes', graph, in RJ Jewell \& AB Fourie (eds), Paste and Thickened Tailings - A Guide, 2nd edn, Australian Centre for Geomechanics, Perth, p. 6.

Zey, W 1999, Putzmeister high density solids pumps: design \& application, page 10, DHW Waiblingen, DHW Waiblingen. 
